\title{
Influence of Swirling Flow Parameters on the Velocity Profile After Local Hydraulic Resistance
}

\author{
Zoran Glavčićc ${ }^{*}$, \\ ${ }^{1}$ Faculty of Mechanical and Civil Engineering in Kraljevo, University of Kragujevac, Serbia, Kraljevo
}

\begin{abstract}
This paper deals with the problem of swirling flow as a transition process after local resistance of a hydraulic system. Since it is a flow phenomenon, it is of most importance to study the velocity profile, and pressure and temperature field. Special attention is given to velocity profile and occurrence of tangent velocity component, in order to get the flow differential equation. Based on obtained flow model and determined swirling parameters, the model simulation is conducted and analysis of some results is done.
\end{abstract}

Keywords: Swirling Flow, Local Resistance, Swirling Flow Parameters, Swirling Intensity

\section{INTRODUCTION}

Swirling flows, being a type of the transition processes within hydraulic systems, from mathematical and physical point of view, represent an exceptionally complex problem for both, the process modeling and simulation and optimization of the flow parameters.

To take into account the occurrence of swirling flow immediately after local resistance, it is necessary to include some assumptions which have to be physically justified. Such approach in setting up the model was used in [7] and [8].

In this paper, the influence of the temperature is taken into account by coefficient of viscosity. Many authors used different approaches in modelling the swirling flows and some examples are [2], [4] and [5].

The contribution of presented model and the upgrade in relation to recent researches are swirling flow parameters, especially described in this paper. Namely, this particularly is referred to following parameters: swirling flow parameter, swirling intensity and swirling flux.

The simulation of developed model can be performed in many ways and with various combinations of flow parameters. The paper shows one of those ways, based on the influence of swirling flow intensity, while indepth analysis should be the subject of further work and research.

\section{MATHEMATICAL MODEL}

The initial equation for foundation of physicalmathematical model that describes the swirling flow behavior after the local resistance is the equation for the kinetic energy change [7]

$$
\int_{A}\left[\left(\rho \frac{v^{2}}{2}+p-\rho U\right) \vec{v} \cdot \vec{n}-\vec{\tau}_{n} \cdot \vec{v}\right] d A+\int_{V}\left[\rho \frac{\partial}{\partial t}\left(\frac{v^{2}}{2}\right)+\Phi\right] d V=0,
$$

As presented in [8], the swirling flow occurs after local resistance, which is defined by parameters, analyzed in [7] and [8] . form

The parameter of swirling flow has the following

$$
\Omega=\frac{\dot{\mathrm{V}}}{\mathrm{R} \bar{\Gamma}}=\frac{\int_{0}^{\mathrm{R}} \mathrm{v}_{\mathrm{x}} \mathrm{rdr}}{\mathrm{R} \int_{0}^{\mathrm{R}} \mathrm{rv}_{\varphi} \mathrm{v}_{\mathrm{x}} \mathrm{rdr}},
$$

where $\bar{\Gamma}=\frac{4 \pi^{2}}{\dot{\mathrm{V}}} \int_{0}^{\mathrm{R}} \mathrm{r}^{2} \mathrm{v}_{\varphi} \mathrm{v}_{\mathrm{x}} \mathrm{dr}-$ averaged unit circulation (average circulation).

The other two swirling parameters are the swirling intensity $\Theta$ and the swirling flux $\mathrm{S}$.

$$
\begin{gathered}
\Theta=\frac{\int_{A} v_{\varphi}^{2} v_{x} d A}{\int_{A} v_{x}^{3} d A}=\frac{\int_{0}^{R} v_{\varphi}^{2} v_{x} r d r}{\int_{0}^{R} v_{x}^{3} r d r} . \\
S=\frac{\int_{A} r v_{\varphi} v_{x} d A}{\int_{A} v_{x}^{2} d A}=\frac{\int_{0}^{R} r^{2} v_{\varphi} v_{x} d r}{r v_{x}^{2} d r},
\end{gathered}
$$

These three parameters are used for definition of all other properties of swirling flow and, therefore, they are called the integral parameters of swirling flow.

Surface integral that has to be defined has the form $\int_{\mathrm{A}} \vec{\tau}_{\mathrm{n}} \cdot \overrightarrow{\mathrm{v}} \mathrm{dA}$. Within tensor notation, this integral can be written as

$$
\int_{\mathrm{A}} \vec{\tau}_{\mathrm{n}} \cdot \overrightarrow{\mathrm{v}} \mathrm{dA}=\int_{\mathrm{A}} \tau_{\mathrm{ij}} \mathrm{v}_{\mathrm{i}} \mathrm{n}_{\mathrm{j}} \mathrm{dA},
$$

i.e., in adopted coordinate system it is $(\mathrm{x}, \mathrm{r}, \varphi)$

$$
\int_{A} \tau_{i j} v_{i} n_{j} d A=\iint_{A}\left[\tau_{\varphi x} v_{\varphi} n_{x}+\left(\tau_{x r} v_{x}+\tau_{\varphi r} v_{\varphi}\right) n_{r}+\tau_{x \varphi} v_{x} n_{\varphi}\right\rfloor d A .
$$

Total control surface consists of three surfaces 
$\mathrm{A}=\mathrm{A}_{1}+\mathrm{A}_{2}+\mathrm{A}_{\mathrm{w}}$.

At the wall of the pipes there is $v_{x}=v_{\varphi}=0$, so it is

$$
\int_{A_{W}} \tau_{i j} v_{i} n_{j} d A=0
$$

For remaining two surfaces it is

$$
\int_{\mathrm{A}} \tau_{\mathrm{ij}} \mathrm{v}_{\mathrm{i}} \mathrm{n}_{\mathrm{j}} \mathrm{dA}=\int_{\mathrm{A} 2} \tau_{\varphi \mathrm{x}} \mathrm{V}_{\varphi} \mathrm{dA}-\int_{\mathrm{A} 1} \tau_{\varphi \mathrm{x}} \mathrm{V}_{\varphi} \mathrm{dA} .
$$

$$
\begin{aligned}
& \int_{A} \tau_{i j} v_{i} n_{j} d A=\int_{A 2} \eta \frac{\partial v_{\varphi}}{\partial x} v_{\varphi} d A-\int_{A 1} \eta \frac{\partial v_{\varphi}}{\partial x} v_{\varphi} d A= \\
& \int_{A 2} \frac{1}{2} \eta \frac{\partial^{2} v_{\varphi}}{\partial x^{2}} d A-\int_{A 1} \frac{1}{2} \eta \frac{\partial^{2} v_{\varphi}}{\partial x^{2}} d A,
\end{aligned}
$$

i.e.

$$
\int_{\mathrm{A}} \tau_{\mathrm{ij}} \mathrm{v}_{\mathrm{i}} \mathrm{n}_{\mathrm{j}} \mathrm{dA}=\int_{\mathrm{A} 2} \eta \frac{\partial}{\partial \mathrm{x}}\left(\frac{\mathrm{v}_{\varphi}^{2}}{2}\right) \mathrm{dA}-\int_{\mathrm{A} 1} \eta \frac{\partial}{\partial \mathrm{x}}\left(\frac{\mathrm{v}_{\varphi}^{2}}{2}\right) \mathrm{dA} .
$$

Since the component of stress tensor is $\tau_{\varphi x}=\eta \frac{\partial v_{\varphi}}{\partial x}$, previous equation reads as follows

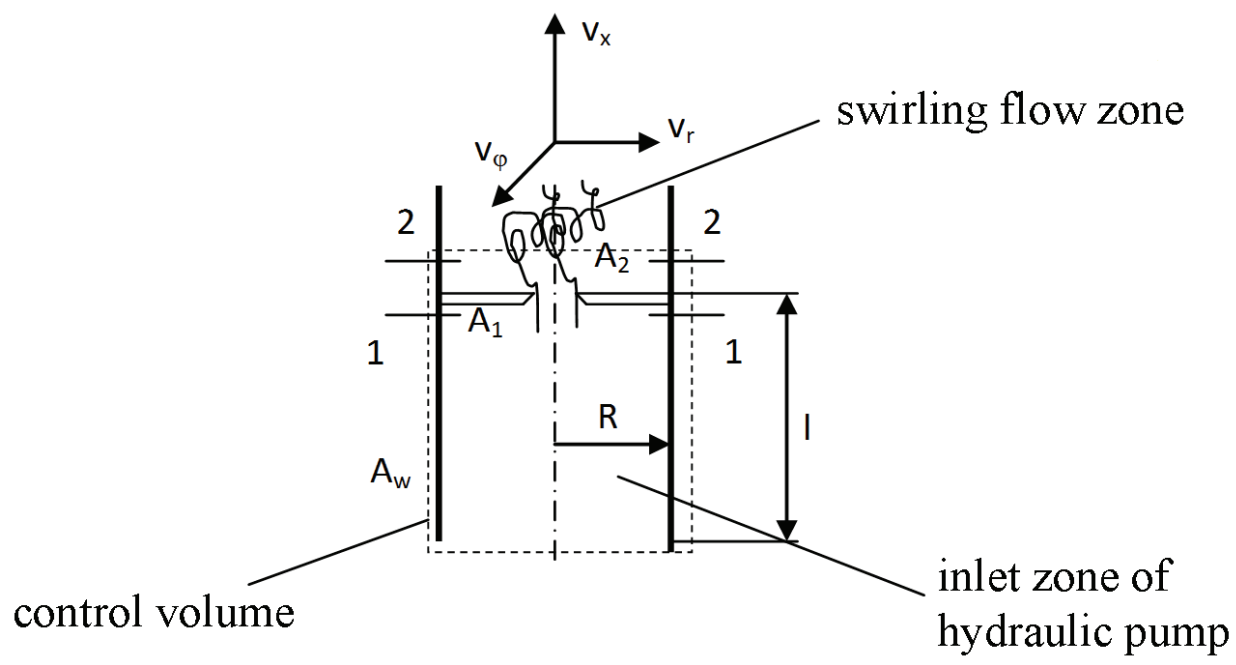

Fig. 1 The occurrence of swirling flow after local resistance

Thus, the effect of tangent stresses is reduced to the change of the kinetic energy in circumferential direction between cross-sections 1-1 and 2-2. Certainly, if the conduit length is small, along which the velocity circumferential component does not change, i.e., if there is $\mathrm{V}_{\varphi} \neq \mathrm{V}_{\varphi}(\mathrm{x})$, that is

$$
\int_{\mathrm{A}} \tau_{\mathrm{ij}} \mathrm{V}_{\mathrm{i}} \mathrm{n}_{\mathrm{j}} \mathrm{dA}=0
$$

In this way, all surface integrals are defined. Yet, two volume integrals remain to be defined.

The first one has the following form

$$
\int_{\mathrm{V}} \rho \frac{\partial}{\partial \mathrm{t}}\left(\frac{\mathrm{V}^{2}}{2}\right) \mathrm{dV}=\frac{\partial}{\partial \mathrm{t}} \int_{\mathrm{V}} \rho \frac{\mathrm{V}^{2}}{2} \mathrm{dV},
$$

and presents the kinetic energy derivative upon time in the considered volume. Previous expression is transformed into the following form

$$
\frac{\partial}{\partial t} \int_{V} \rho \frac{v^{2}}{2} d V=\frac{\partial}{\partial t} \int_{x} \frac{\rho}{2}\left[\int_{A} v^{2} d A\right] d x .
$$

Introducing the one-dimension flow, Boussinesq's coefficient apperas in the brackets of previous expression, whose form is

$$
\beta_{\mathrm{v}}=\frac{1}{\mathrm{Au}^{2}} \int_{\mathrm{A}} \mathrm{v}^{2} \mathrm{dA}
$$

i.e., for straight pipe with circular cross-section

$$
\beta_{\mathrm{v}}=\frac{2}{\mathrm{R}^{2} \mathrm{u}^{2}} \int_{0}^{\mathrm{R}} \int_{\mathrm{A}} \mathrm{v}^{2} \mathrm{rdr},
$$

where subscript "v" stands for swirling flow. The following form is obtained

$$
\frac{\partial}{\partial t} \int_{V} \rho \frac{v^{2}}{2} d V=\frac{\rho}{2} \int_{x} A \frac{\partial}{\partial t}\left(\beta_{v} u^{2}\right) d x
$$

i.e. 


$$
\frac{\partial}{\partial t} \int_{V} \rho \frac{v^{2}}{2} d V=\frac{\rho}{2} \int_{x 1}^{x 2} A\left(u^{2} \frac{\partial \beta_{v}}{\partial t}+2 \beta_{v} u \frac{d u}{d t}\right) d x
$$
form

The last equation simply transformes into the

$$
\frac{\partial}{\partial t} \int_{V} \rho \frac{v^{2}}{2} d V=\frac{1}{2} \rho u^{2} A \int_{x} \frac{\partial \beta_{v}}{\partial t} d x+\rho u \frac{d u}{d t} \int_{x} \beta_{v} d x
$$

Finally, the second volume integral is to be defined, which means the modeling of function of energy dissipation. The energy dissipation can be formulated in terms of stress tensor and tensor of deformation velocity, i.e.

$$
\int_{\mathrm{V}} \Phi \mathrm{dV}=\int_{\mathrm{V}} \tau_{\mathrm{ij}} \dot{\mathrm{s}}_{\mathrm{ij}} \mathrm{dV}
$$

Thus, the dissipation function is as follows

$$
\Phi=\tau_{\mathrm{ij}} \dot{\mathrm{s}}_{\mathrm{ij}}=\tau_{\mathrm{ij}} \frac{\partial \mathrm{v}_{\mathrm{i}}}{\partial \mathrm{x}_{\mathrm{j}}},
$$

and for the Newton and incompressible fluid it is

$$
\Phi=\frac{1}{2} \eta\left(\frac{\partial \mathrm{v}_{\mathrm{i}}}{\partial \mathrm{x}_{\mathrm{j}}}+\frac{\partial \mathrm{v}_{\mathrm{j}}}{\partial \mathrm{x}_{\mathrm{i}}}\right)^{2} .
$$

For cylindrical coordinate system we have

$$
\Phi=\eta\left[2\left(\frac{\partial \mathrm{v}_{\mathrm{x}}}{\partial \mathrm{x}}\right)^{2}+\left(\frac{\partial \mathrm{v}_{\varphi}}{\partial \mathrm{r}}-\frac{\mathrm{v}_{\varphi}}{\mathrm{r}}\right)^{2}+\left(\frac{\partial \mathrm{v}_{\varphi}}{\partial \mathrm{x}}\right)^{2}+\left(\frac{\partial \mathrm{v}_{\mathrm{x}}}{\partial \mathrm{r}}\right)^{2}\right] .
$$

According to previously addopted assumption where $\mathrm{v}_{\mathrm{r}}=0$, which imposes that $\frac{\partial \mathrm{v}_{\mathrm{x}}}{\partial \mathrm{x}}=0$, the expression gets the form

$$
\Phi=\eta\left[\left(\frac{\partial \mathrm{v}_{\varphi}}{\partial \mathrm{r}}-\frac{\mathrm{v}_{\varphi}}{\mathrm{r}}\right)^{2}+\left(\frac{\partial \mathrm{v}_{\mathrm{x}}}{\partial \mathrm{r}}\right)^{2}\right],
$$

where the member $\left(\frac{\partial v_{\varphi}}{\partial x}\right)^{2}$ is neglected, because of its less order in comparison to other two members, according to assumption where $\mathrm{v}_{\varphi} \neq \mathrm{v}_{\varphi}(\mathrm{x})$.

Thus,

$$
\int_{\mathrm{V}} \Phi \mathrm{dV}=\eta \int_{\mathrm{V}}\left[\left(\frac{\partial \mathrm{v}_{\varphi}}{\partial \mathrm{r}}-\frac{\mathrm{v}_{\varphi}}{\mathrm{r}}\right)^{2}+\left(\frac{\partial \mathrm{v}_{\mathrm{x}}}{\partial \mathrm{r}}\right)^{2}\right] \mathrm{dV} .
$$

Analogous to developing the expression for dissipation, developing of expression for axial flow is based upon swirling flow integral parameters in following form

$$
\frac{1}{\dot{\mathrm{V}}} \int_{\mathrm{V}} \Phi \mathrm{dV}=\lambda_{\mathrm{v}} \frac{\rho \mathrm{u}^{2}}{2} .
$$

So, if the velocity components profiles are known, it is convinient to use the last expression. If this is not the case, the dissipation is presented via swirling flow integral parameter. Along with that, the coefficient of loss of swirling flow total energy is actually expressed via coefficient of swirling flow friction $\lambda_{\mathrm{v}}$.

After each member is analyzed, the mathematical model for the swirling flow after local resistance in hydraulic - pneumatic system can be formulated. Including all modeled members in equation, the mathematical model for swirling flow is obtained as follows

$$
\begin{aligned}
& \rho\left(\alpha_{v 2} \frac{u_{2}^{2}}{2}-\alpha_{v 1} \frac{u_{1}^{2}}{2}\right)+\left(p_{2}-p_{1}\right)+\rho\left(U_{2}-U_{1}\right) \\
& +\frac{1}{2} u^{2} \int_{x} \frac{\partial \beta_{v}}{\partial x} d x+\rho \frac{d u}{d t} \int_{x} \beta_{v} d x+\lambda_{v} \frac{\rho u^{2}}{2}=0 .
\end{aligned}
$$

Variables in this equation are averaged axial components of velocity, i.e. the current average velocity $\boldsymbol{u}$ and its time derivative $\boldsymbol{d} \boldsymbol{u} / \boldsymbol{d} \boldsymbol{t}$. Besides that, there are also current values of velocities in cross-sections 1-1 and $2-2, \mathrm{u}_{1}$ and $\mathrm{u}_{2}$ respectively, which make difficulties in forming the differential equation that would depend on velocity and its first time derivative. Because of that, expressions that use the total flow energy are preferred. By using them, the equation can be written as

$$
\xi_{v} \rho \frac{u^{2}}{2}+\frac{1}{2} u^{2} \int_{x} \frac{\partial \beta_{v}}{\partial t} d x+\rho \frac{d u}{d t} \int_{x} \beta_{v} d x+\lambda_{v} \frac{\rho u^{2}}{2}=0
$$

Boussinesq's coefficient of swirling flow $\beta_{\mathrm{v}}$ apperas in this equation. The dependence of Boussinesq's coefficient on the swirling flow integral parameters is not defined in the literature. However, the dependence for Coriolis coefficient exists. Namely, research $[\mathrm{xx}]$ shows, based on experiments, that there exists the following relation

$$
\alpha_{\mathrm{v}}=\alpha+\mathrm{A}_{\alpha} \mathrm{e}^{-0,012 \Omega_{0}^{0,34} \frac{\mathrm{x}}{\mathrm{R}}}
$$

Where: $\mathrm{A} \alpha$ - coefficient, $\alpha$ - Coriolis coefficient of axial non-swirling flow.

Thus, for further equation analysis, it is necessary to define Boussinesq's coefficient for swirling flow in terms of already presented integral parameters. 


\section{Relation \\ $\beta_{\mathrm{v}}=\mathrm{f}\left(\alpha_{\mathrm{v}}\right)$.}

shows that there is a correlation between Boussinesq's and Coriolis coefficient. Namely, if axial velocity is written in term of deviation $\varepsilon$

$\mathrm{V}_{\mathrm{x}}=\mathrm{u}+\varepsilon$,

where

$\int_{\mathrm{A}} \varepsilon \mathrm{dA}=0$

Coriolis coefficient of axial non-swirling flow reads

$$
\alpha=\frac{1}{\mathrm{Au}^{3}} \int_{\mathrm{A}}(\mathrm{u}+\varepsilon)^{3} \mathrm{dA} .
$$

By further transformation, where it is considered that $\varepsilon^{3} \approx 0$, it is obtained

$$
\alpha \approx 1+\frac{3}{\mathrm{Au}^{2}} \int_{\mathrm{A}} \varepsilon^{2} \mathrm{dA} .
$$

Similiar to previous, Boussinesq's coefficient reads

$$
\beta=\frac{1}{A u^{2}} \int_{A}(u+\varepsilon)^{2} d A,
$$
we obtain

out of which, through algebraic transformations,

$$
\beta \approx 1+\frac{1}{\mathrm{Au}^{2}} \int_{\mathrm{A}} \varepsilon^{2} \mathrm{dA} .
$$

Comparing the expressions for $\alpha$ and $\beta$, it can be noted

$$
\alpha \approx 3 \beta-2
$$

For the swirling flow, with separated influences of axial and circumferential flow components, it can be written

$$
\begin{aligned}
& \alpha_{v}=\frac{1}{A u^{3}}\left(\int_{A} v_{x}^{3} d A+\int_{A} v_{\varphi}^{2} v_{x} d A\right), \\
& \beta_{v}=\frac{1}{A u^{2}}\left(\int_{A} v_{x}^{2} d A+\int_{A} v_{\varphi}^{2} d A\right) .
\end{aligned}
$$
following

$$
\begin{aligned}
& \alpha_{v}=\frac{1}{A u^{3}}\left[\int_{A} v_{x}^{3} \mathrm{dA}\left(1+\frac{\int_{A} v_{\varphi}^{2} v_{x} d A}{\int_{A} v_{x}^{3} d A}\right)\right], \\
& \beta_{v}=\frac{1}{A u^{2}}\left[\int_{A} v_{x}^{2} d A\left(1+\frac{\int_{A} v_{\varphi}^{2} d A}{\int_{A} v_{x}^{2} d A}\right)\right] .
\end{aligned}
$$

Based upon previous expressions, we obtain dependences

$$
\alpha_{\mathrm{v}}=\alpha(1+\Theta)
$$

$$
\beta_{\mathrm{v}}=\beta\left(1+\frac{\int_{\mathrm{A}} \mathrm{v}_{\varphi}^{2} \mathrm{dA}}{\int_{\mathrm{A}} \mathrm{v}_{\mathrm{x}}^{2} \mathrm{dA}} .\right.
$$

The following coefficient can be determined

$$
E_{v}=\frac{\int_{A} v_{\varphi}^{2} d A}{\int_{A} v_{x}^{2} d A},
$$

that can be named the energy parameter of swirling flow, as it is a ratio between kinetic energy of circumferential flow and kinetic energy of axial flow. Its higher value means higher value of circumferential component of velocity of swirling flow, i.e. more intense swirling. Futhermore, it is obtained

$$
\beta_{\mathrm{v}}=\beta\left(1+\mathrm{E}_{\mathrm{v}}\right) \text {. }
$$

that is

$$
\int_{0}^{\mathrm{R}} \mathrm{r}^{2} \mathrm{v}_{\varphi} \mathrm{v}_{\mathrm{x}} \mathrm{dr}=\mathrm{SR} \int_{0}^{\mathrm{R}} \mathrm{v}_{\mathrm{x}}^{2} \mathrm{rdr}
$$

Embedding previous expression in the expression for swirling flow parameter, it is obtained

$$
\Omega=\frac{\dot{\mathrm{V}}^{2}}{4 \pi \mathrm{R}^{2} \mathrm{~S} \int_{0}^{\mathrm{R}} \mathrm{v}_{\mathrm{x}}^{2} \mathrm{rdr}},
$$

out of which, by algebraic transformations, we get the following dependance

$$
\Omega=\frac{1}{2 \mathrm{~S} \beta},
$$


out of which it can be concluded

$$
\beta=\frac{1}{2 \Omega S} .
$$

Hence, Boussinesq's coefficient for non-swirling axial flow depends on swirling flow integral parameters.

It is possible now to find the dependence $\beta_{\mathrm{v}}=\mathrm{f}\left(\alpha_{\mathrm{v}}\right)$.

Based on previous expression, it is

$$
\alpha=\frac{\alpha_{\mathrm{v}}}{1+\Theta} .
$$

From last relations, we can write

$$
\frac{\alpha_{v}}{1+\Theta}=\frac{3}{2 \Omega S}-2
$$

or

$$
\alpha_{v}=(1+\Theta)\left(\frac{3}{2 \Omega S}-2\right) \text {. }
$$

The last expression is to be incorporated in integral expression and, by few algebraic transformations, it can be written

$$
\begin{aligned}
& \beta_{v}=\frac{\left(1+E_{v}\right)}{3}\left(\frac{3}{2 \Omega S}-4\right) \text { or } \\
& \beta_{\mathrm{v}}=\frac{\left(1+E_{v}\right)}{3}\left(\frac{\alpha_{v}}{1+\Theta}-2\right) .
\end{aligned}
$$

By algebraic transformations, the swirling flux $\mathrm{S}$ swirling parameter $\Omega$ are related through following equation

$$
\mathrm{S}=\frac{3}{1+8 \Omega}
$$

Finally, by embedding the introduced expressions in the equation, a differential equation is derived as follows

$$
\begin{aligned}
& {\left[\frac{\rho\left(1+\mathrm{E}_{\mathrm{v}}\right)}{3}\left(\frac{\alpha 1}{1+\Theta}+21+\frac{\mathrm{RA}_{\alpha}}{0,012 \Omega_{0}{ }^{0,34}(1+\Theta)}-\frac{\mathrm{RA}_{\alpha}}{0,012 \Omega_{0}{ }^{0,34}(1+\Theta)} \mathrm{e}^{-0,012 \Omega_{0}{ }^{0,34} \frac{1}{\mathrm{R}}}\right] \frac{\mathrm{du}}{\mathrm{dt}}+\right.} \\
& +\left[\frac{\rho \zeta}{2}\left(1+\frac{3,7}{\Omega_{0}{ }^{1,84}}\right)+\frac{\rho \lambda}{2}\left(1+\frac{1,82}{\left.\left.\Omega_{0}{ }^{1,98} \mathrm{e}^{-0,007 \Omega_{0}{ }^{-0,04}\left(\frac{1}{1+8 \Omega_{0}}\right)^{-0,05} \frac{1}{\mathrm{R}}}\right)+\frac{1}{6} 1 \Omega_{0} \mathrm{SA}_{\alpha} \mathrm{e}^{-0,012 \Omega_{0}{ }^{0,34} \frac{1}{\mathrm{R}}}\right] \mathrm{u}^{2}=0}\right]\right.
\end{aligned}
$$

The differential equation presents the mathematical model which describes the non-stationary swirling flow after local resistance. The basic feature of presented equation is the fact that physically measurable parameter $\Omega_{0}$ is dominant.

\section{MODEL SIMULATION AND ANALYSIS OF OBTAINED RESULTS}

Simulation of the model is conducted in MatLAB, i.e. in SimuLink. Flow paramaters, in relation to which the investigation of distribution of flow velocity after local resistance is carried out, are

- $\quad$ Swirling flow parameter $\Omega$,

- $\quad$ Swirling inensity $\Theta \mathrm{i}$

- Swirling flux S.

The variations of given parameters are made in the early phase of presented investigation, which has led to diagrams for distribution of non-dimensional flow velocity in relation to particular values of mentioned parameters.
The number of possible combinations of parameters variations is very large, hence, herein are just some of them.

Fig. 2 shows the distribution of non-dimensional velocity for the case $\Omega_{0}=2.5$. Dashed curve stands for the velocity distribution for Coriolis coefficient $\alpha=30$, and the lowest continuous thin curve is for velocity distribution for Coriolis coefficient $\alpha=10000$.

In Fig. 3, the value of parameter $\Omega_{0}$ is increased to 22.5 , whereby the positions of curves for boundary values of parameter $\alpha$ (30 and 10000) are inversed. In both cases, the values of swirling inensity $\Theta$ and swirling flux $\mathrm{S}$ remain unchanged.

Thus, the idea came up to search the value of parameter $\Omega_{0}$ for which the curves will overlap, i.e. for which the velocity distribution will be the same. By investigation, it is found that the value is $\Omega_{0}=5.5$, as depicted in Fig. 4. 


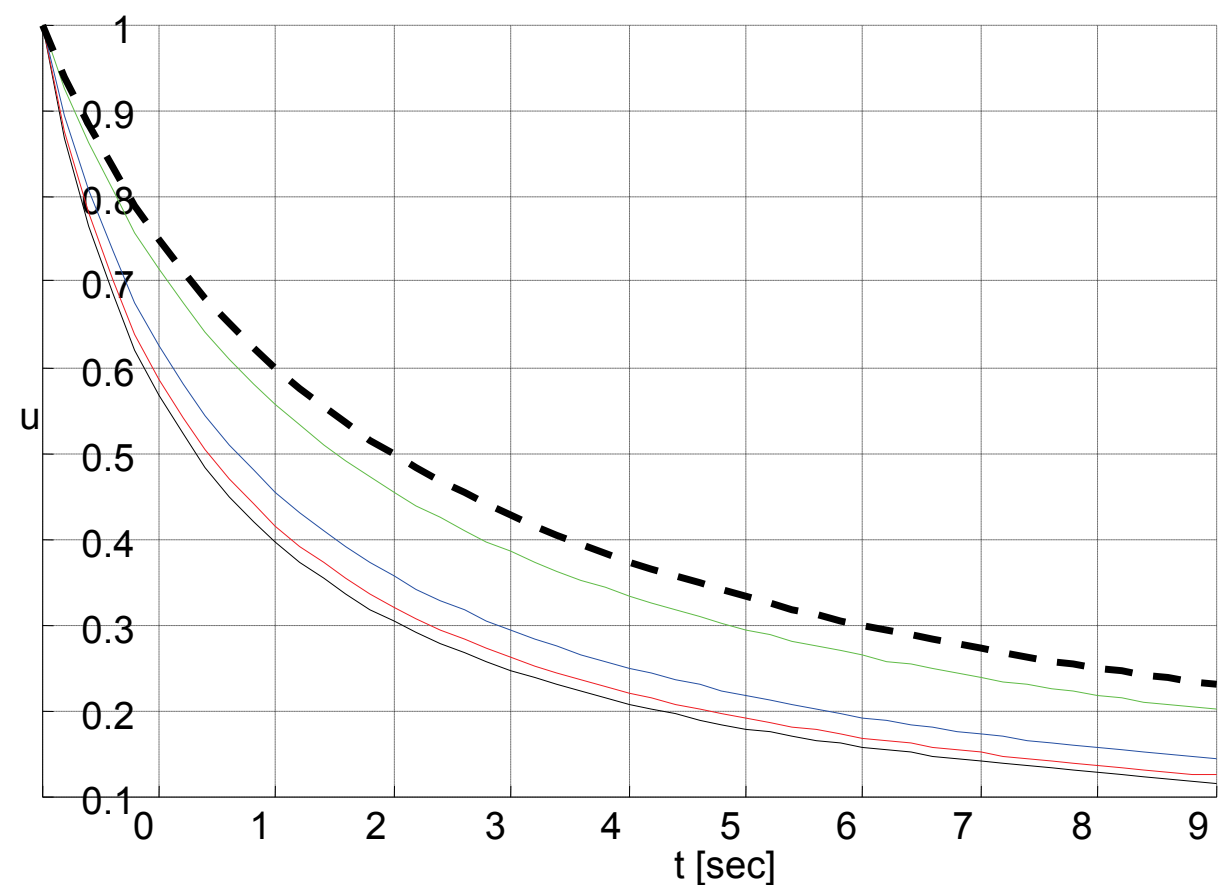

A_alpha $=\left[\begin{array}{lllll}30 & 300 & 1000 & 5000 & 10000\end{array}\right]$;

OMEGA $0=2.5$;

$\mathrm{THETA}^{-}=0.2$;

$\mathrm{S} \quad=0.5$;

Fig. 2 Non-dimensional flow velocity distribution for $\Omega_{0}=2.5$

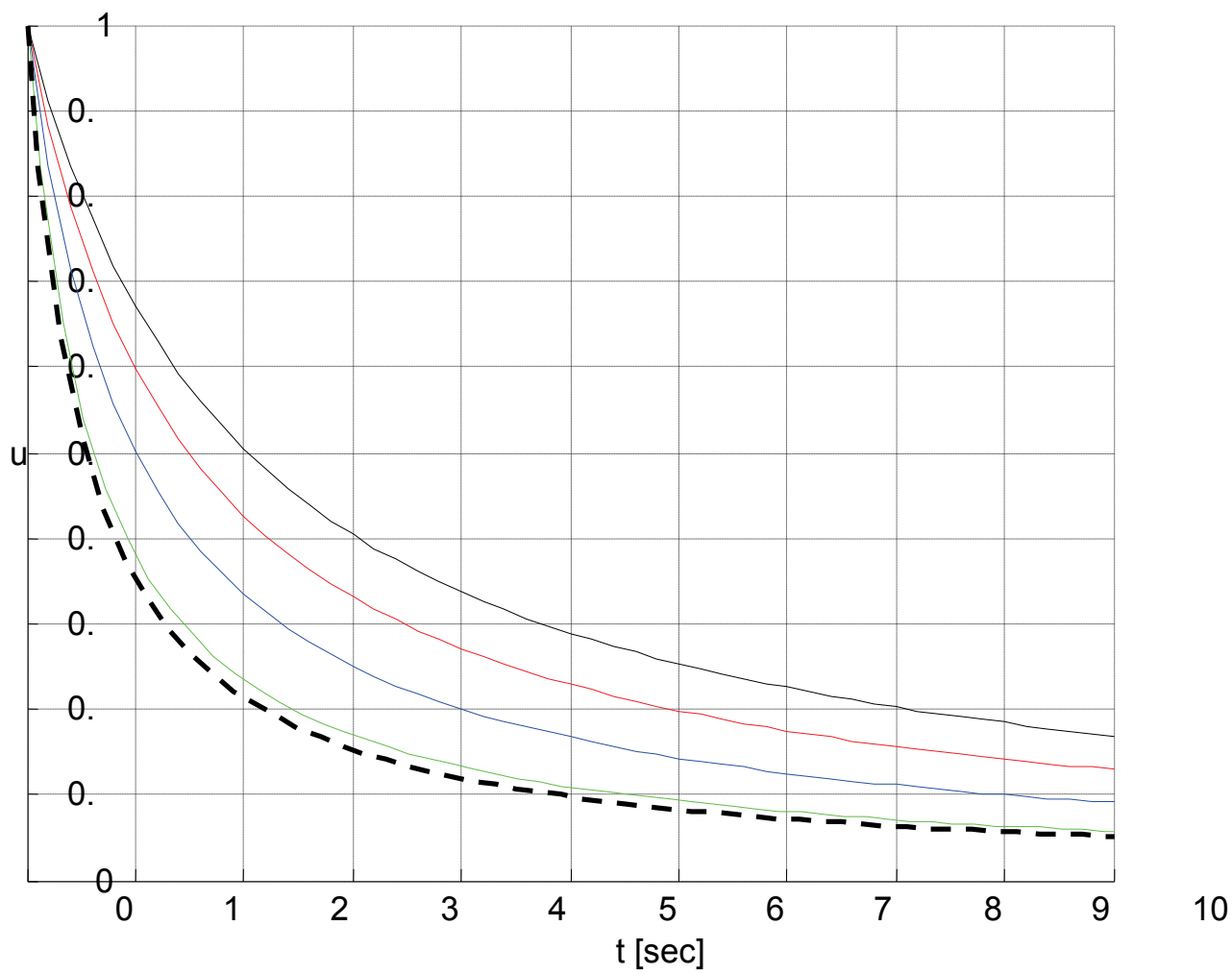

A alpha $=\left[\begin{array}{llllll}30 & 300 & 1000 & 5000 & 10000\end{array}\right]$;

OMEGA_O $=22.5$;

THETA $^{-}=0.2$;

$\mathrm{S} \quad=0.5$;

Fig. 3 Non-dimensional flow velocity distribution for $\Omega_{0}=22.5$ 

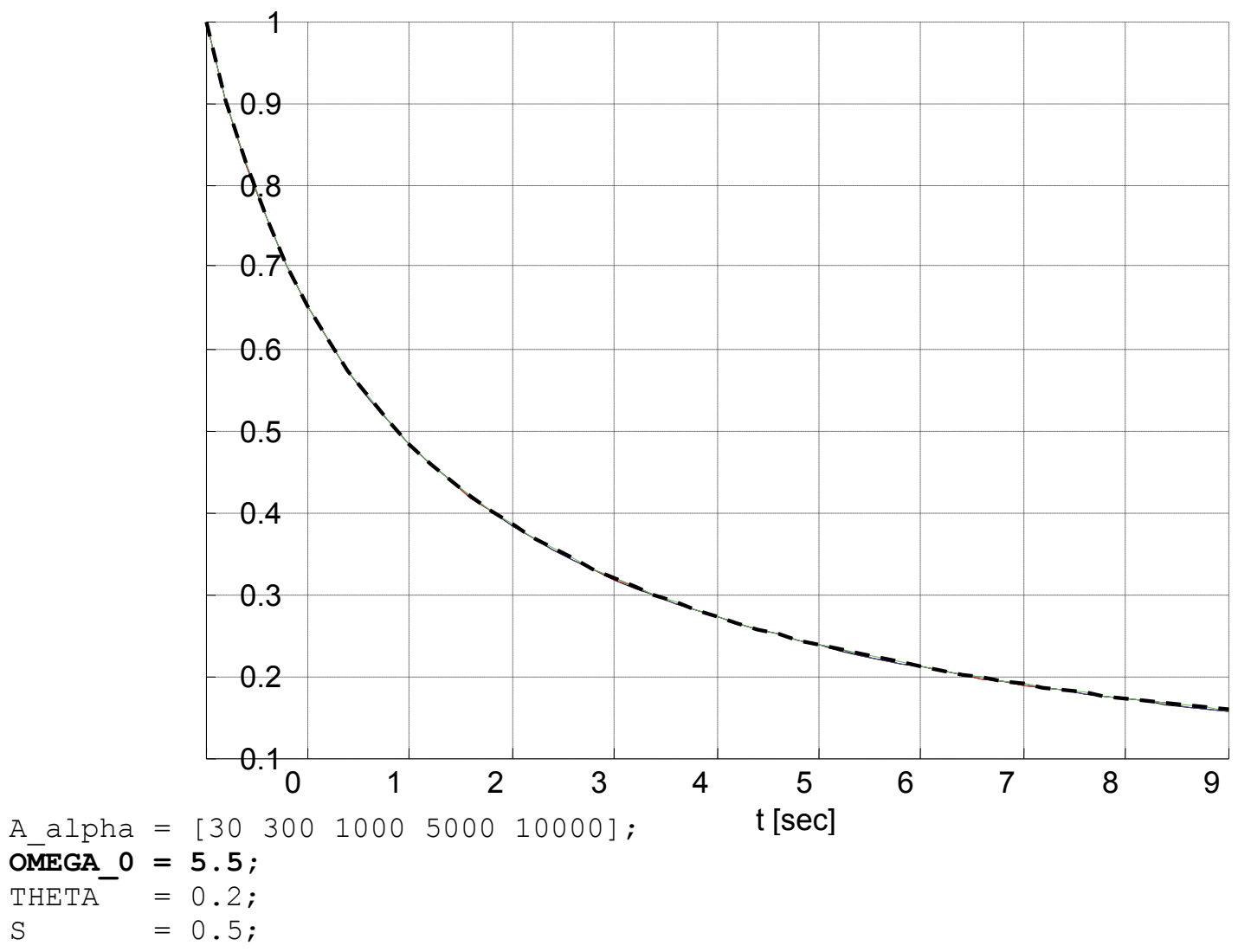

Fig. 4 Non-dimensional flow velocity distribution for $\Omega_{0}=5.5$

As depicted in Fig. 4, the velocity distributions in swirling flow for all values of Coriolis coefficient are identical if the swirling flow parameter takes the value $\Omega_{0}=5.5$.
In Fig. 5, the value of swirling flow parameter is $\Omega_{0}=5.5$, but the swirling flux value is changed to $\mathrm{S}=4$, which caused the change in distribution of fluid flow velocity after the local resistance.
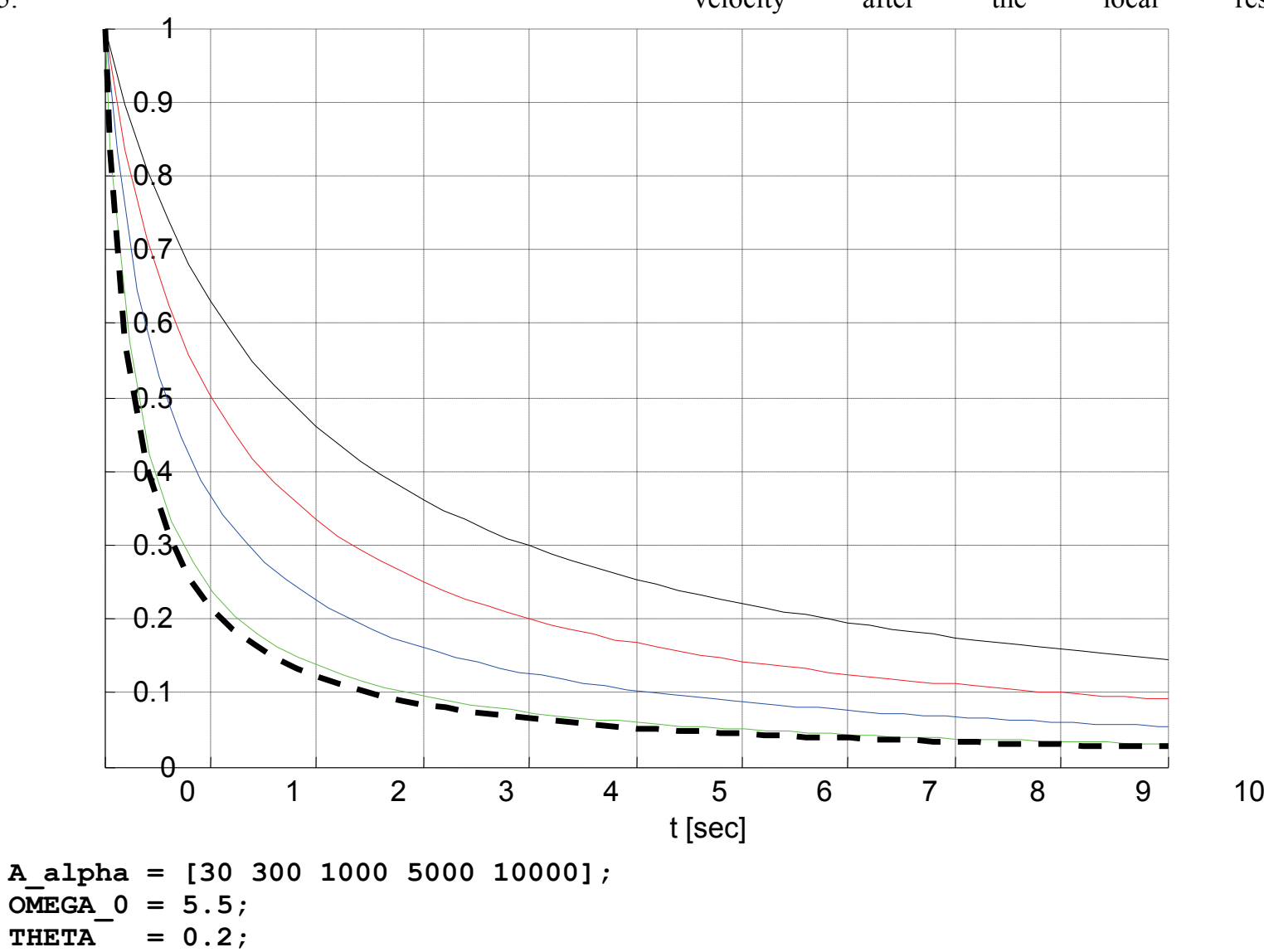

Fig. 5 Non-dimensional flow velocity distribution for $S=4$ 
Certainly, various combinations of influential coefficients are possible, which lead to many different distributions of velocity. This is a subject to some further investigations in this domain.

\section{CONCLUSION}

Research in the domain of swirling flow, through analysis of parameters that are originally presented in this paper, yields a great number of possible variations. The conclusions made upon these investigations should advance the knowledge in the field of fluid swirling flow.

The main advantage of this applied approach is in the fact that the distribution of circumferential velocity component in swirling flow is not limited by any assumption, which is the most complex part within the swirling modelling.

In brief, the swirling parameter $\Omega_{0}$ has the greatest influence on non-stationary swirling flow behaviour. This parameter represents the influence of flow as an engineering feature, which can be of great practical importance.

\section{REFERENCES}

[1] Tae-Hyun Chang, Chang-Hoan Lee. (2010) Swirling Flow in Tubes with Sudden Expansion by Using 3D Particle Image Velocimetry Technique, Communications in Computer and Information Science, Volume 342, pp. 90-95.
[2] James D. Van de Ven, INCREASING HYDRAULIC ENERGY STORAGE CAPACITY: FLYWHEELACCUMULATOR, International Journal of Fluid Power, ISSN 1439-9776, Volume 10, November 2009.

[3] Tae-Hyun Chang, An Investigation of Heat Transfer Characteristics of Swirling Flow in a $180^{\circ}$ Circular Section Bend with Uniform Heat Flux, KSME International Journal, Volume 17, No. 10, pp. 15201532, 2003.

[4] Tae-Hyun Chang, Kwon-Soo Lee, An experimental study of swirling flow in a cylindrical annuli using the PIV technique, The Visualization Society of Japan, pp 293-301, 2010B.B.

[5] Tae-Hyun Chang, Kwon-Soo Lee, An experimental study of swirling flow in a cylindrical annuli using the PIV technique, The Visualization Society of Japan, pp 293-301, 2010B.B.

[6] V.V. Salomatov, D. V. Krasinskii, Yu. A. Anikin, I. S. Anufriev, O. V. Sharypov, Kh. Enhzhargal, Experimental and Numerical Investigation on Aerodynamic Characteristics of Swirling Flows in a Model of the Swirling-Type Furnace of a Steam Generator, Journal of Engineering Physics and Thermophysics, Vol. 85, No. 2. 2012.

[7] Glavčić Zoran, Fizičko - matematičko modeliranje prelaznih procesa $\mathrm{u}$ hidrauličko - pneumatskim sistemima, Magistarski rad, Beograd, 2000.

[8] Miroslav Benišek, Istraživanje vihornog strujanja u pravim cevima kružnog preseka, Doktorska disertacija, Beograd, 1979. 